\title{
BMJ Open Who is in control? Clinicians' view on their role in self-management approaches: a qualitative metasynthesis
}

\author{
Suzie Mudge, ${ }^{1}$ Nicola Kayes, ${ }^{1}$ Kathryn McPherson ${ }^{1,2}$
}

To cite: Mudge S, Kayes N, McPherson K. Who is in control? Clinicians' view on their role in selfmanagement approaches: a qualitative metasynthesis. BMJ Open 2015;5:e007413. doi:10.1136/bmjopen-2014007413

\section{- Prepublication history and additional material is available. To view please visit the journal (http://dx.doi.org/ 10.1136/bmjopen-2014- 007413).}

Received 11 December 2014 Revised 17 March 2015 Accepted 13 April 2015

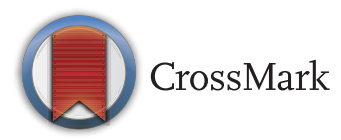

${ }^{1}$ Centre for Person Centred Research, Faculty of Health and Environmental Science, AUT University, Auckland, New Zealand

${ }^{2}$ Health Research Council of New Zealand, Auckland, New Zealand

Correspondence to Dr Suzie Mudge; suzie.mudge@aut.ac.nz

\section{ABSTRACT}

Objective: To explore clinician perceptions of involvement in delivery of self-management approaches.

Setting: All healthcare settings.

Design: EBSCO, Scopus and AMED databases were searched, in July 2013, for peer-reviewed studies in English reporting original qualitative data concerning perceptions of clinicians regarding their involvement in or integration of a self-management approach. Of 1930 studies identified, 1889 did not meet the inclusion criteria. Full text of 41 studies were reviewed by two independent reviewers; 14 papers were included for metasynthesis. Findings and discussion sections were imported into Nvivo-10 and coded line-by-line. Codes were organised into descriptive themes and crosschecked against original sources to check interpretation, and refined iteratively until findings represented an agreed understanding. Studies were appraised for quality.

Results: Delivering self-management in practice appeared to be a complex process for many clinicians. The issue of 'control' arose in all studies, both in the qualitative data and authors' interpretations. The first theme: Who is in control?-represented ways clinicians talked of exercising control over patients and the control they expected patients to have over their condition. The second theme: Changing clinician views -reflected what appeared to be an essential transformation of practice experienced by some clinicians in the process of integrating selfmanagement approaches into the practice. A range of challenges associated with shifting towards a selfmanagement approach were reflected in the third theme, Overcoming challenges to change. Tensions appeared to exist around forming partnerships with patients. Strategies found helpful in the process of change included: dedicating time to practice reciprocity in communication style, peer support and selfreflection.

Conclusions: A consistent finding across studies is that 'control' is a key feature of how self-management is viewed by clinicians. They described challenges associated with the paradigm shift required to share or let go of control. Future research should identify whether strategies described by clinicians are key to successful self-management.

\section{Strengths and limitations of this study}

- We used robust methodologies to synthesise raw data and interpretations of authors from 14 studies, including a range of disciplines working with patients with differing conditions. Metasynthesis was used to enable a level of interpretation that goes beyond the findings of the individual studies included.

- Metasyntheses have been criticised due to the perceived risk of synthesising work that comes from varying philosophical or theoretical positions, which may be deemed incompatible. In this instance, none of the included papers were transparent about their philosophical positioning making it difficult to address this explicitly. As such, interpretations should be read with caution. We did, however, remain cognisant of the individual papers' stated aims and purpose, and papers were read and analysed in that context.

- This study is novel by its examination of the view of clinicians involved in self-management approaches and the finding that clinicians' practice is focused on control of patient behaviour. Our study identifies that clinicians may find the shift towards sharing control in healthcare (arguably essential in self-management) a difficult process.

Self-management programmes to assist patients to develop self-management skills to manage chronic health conditions have seen a recent rise in popularity. ${ }^{1-4}$ Much of the appraisal of self-management approaches has centred on efficacy on outcomes with modest results. $^{3-5}$ The effect may be underestimated due to varied conceptualisations of selfmanagement, a wide range of included selfmanagement programmes and varied perspectives regarding what constitutes a good outcome. $^{6}$ Effective self-management programmes are vital to respond to the rising numbers of people living and ageing with long-term and chronic health conditions. A number of studies have explored clinicians' 
perceptions of what patients need to do differently to successfully self-manage, with little obvious examination of the role clinicians play in delivery and potential implications on patient outcomes. ${ }^{6-8}$ There is a need for critical examination of the way in which self-management approaches have been developed and delivered to ensure optimal delivery and outcome.

The views of clinicians who deliver self-management programmes should provide an insight into the potential challenges or barriers to implementing self-management approaches, and the differences or similarities in these approaches to models of practice. Historically, selfmanagement approaches were developed for patients with chronic health conditions such as asthma and diabetes. ${ }^{9}$ Later, these have been embraced in a much wider range of health conditions such as epilepsy, arthritis and stroke. ${ }^{1}{ }^{10-12}$ The aim of this study was to explore the perceptions of clinicians concerning their delivery of a self-management approach in order to inform the development of an intervention; to support clinicians' attempts to integrate principles of selfmanagement into practice. It is possible that much can be learned from considering older and more established self-management approaches and programmes in order to optimise the development and delivery of selfmanagement principles in clinical practice. We have, therefore, deliberately chosen a wide context of condition groups and healthcare professionals in our metasynthesis.

\section{METHODS}

\section{Methodology}

We used metasynthesis as the methodology to synthesise data across multiple studies ${ }^{13}$ and to offer a level of interpretation that goes beyond the findings of the individual studies included. ${ }^{14}{ }^{15}$ Thematic synthesis was the approach used for analysis. ${ }^{15}$

\section{Data sources}

EBSCO, Scopus and AMED databases were searched, in July 2013, using search headings related to selfmanagement, health professional and perception (see online supplementary file 1). Proximity searching, using search terms within five words, was utilised for 'clinician' and 'perception'. The search was limited to qualitative studies. No start date limit was used in the search.

\section{Study selection}

Titles and abstracts were screened by SM to identify studies published in English in a peer-reviewed journal that reported an original qualitative study, with data on the reported beliefs, experiences, perceptions or views of clinicians regarding their role or skills involved in the delivery of a self-management approach. Studies were excluded if the data regarding clinician views could not be distinguished from the views of others (eg, patients or carers), or if the phenomenon of interest was not focused on the clinician's role in delivery of the selfmanagement approach (eg, focused on the mode of delivery such as web-based programme or investigating a theoretical model underpinning a self-management approach).

Full-text articles were retrieved for all the included studies and these were independently reviewed by SM and NK. Discrepancies regarding eligibility for inclusion were resolved initially by discussion and consensus. If consensus could not be reached, the study was referred to KM for adjudication.

Included studies were critically appraised for quality by SM and NK through the use of the Qualitative Findings Critical Appraisal Scale. ${ }^{16}$ If the research methodology was not explicitly stated, then a generic qualitative methodology was assumed for criteria 2-5 of the scale. Discrepancies were resolved through discussion and consensus. Studies were not excluded from consideration based on the quality appraisal in keeping with the methodology; ${ }^{14}{ }^{16}$ however, methodological quality of included papers is reported so that the review findings can be read with that context in mind.

\section{Data extraction and synthesis}

Findings and discussion sections of studies were imported into Nvivo-10 and coded line-by-line. ${ }^{15} \quad 17$ Using this approach, two types of data were produced: (1) raw data reported in included studies, and (2) author interpretations. These were considered as data, and subjected to analysis and interpretation during synthesis. Only meaningful units of data in relation to the study question were coded; for example, demographic data were not coded. More than one code could be assigned to any one unit of text. Codes were then grouped in order to develop descriptive themes. Constant comparison methods were used by analysing subsequent articles in comparison with studies previously coded $^{17}$ in order to 'translate' concepts between studies, ${ }^{15}$ but keeping very close to the original findings of the included studies. Following this process, analytical themes were generated that went beyond the data of the original studies in order to consider the descriptive themes in relation to the question posed by this metasynthesis. ${ }^{15}$ This was achieved through discussion (SM and NK), and by repeatedly comparing emerging analytical themes to descriptive themes and moving iteratively between the raw data and analysis. A draft summary of the findings was written by SM and commented on by NK and KM, and subsequently revised in an iterative way until the document represented an agreed understanding of the analytical findings. Resolution of differences of interpretation was achieved through returning to the data in its original context followed by discussion and writing.

\section{Rigour}

SM kept a log of reflexive questions within Nvivo, which was reviewed and discussed with $\mathrm{NK}$ at intervals. 
We attempted to manage subjectivity by returning to the context of the original data regularly to check interpretations and through regular debriefing with KM.

\section{FINDINGS}

\section{Study selection}

Searching identified 1930 potentially relevant papers, 1817 were excluded after screening of the title and abstract, leaving 41 papers for full-text review. Seventeen papers failed to meet the inclusion criteria (not reporting an original qualitative study, $n=3$; not reporting on data concerning beliefs, experiences, perceptions or views of health professionals regarding their own involvement in delivery or integration of a self-management approach into practice, $n=14$ ). Another 10 papers were excluded (data regarding clinicians' views could not be isolated from the views of others, $n=2$; main phenomenon of interest was not focused on the delivery or integration of the self-management approach, $n=8$ ). This left 14 papers, ${ }^{18-31}$ from which the findings and discussion were extracted as data for this metasynthesis. Figure 1 shows the selection process of the included studies. Critical quality appraisal results for each included study are shown in table 1 . A total quality score has been noted for ease of comparison across studies; however, these scores should be interpreted with caution as it should not be assumed that each of the quality criteria should be given equal weighting. Generally the studies were of moderately high quality; 13 of the 14 studies met at least 7 of the 10 quality criteria. Key limitations were the lack of explicitly stated philosophical positioning of the research and statements to locate the researchers culturally or theoretically.

\section{Description of studies}

Table 2 provides an overview of each study, including the patient groups targeted by the self-management programmes, the context of the study (country and setting), the aim of the study and the clinicians involved. Overall, 287 clinician participants took part in the included studies. Six of the 14 studies included clinicians of a single discipline, all of whom were nurses. ${ }^{18} 2326282931$ The remaining 8 studies had a mix of disciplines: most commonly nurses (in 10 studies), ${ }^{18}$ 20-23 26-29 31 medical doctors (in 5 studies), ${ }^{19} 20222730$ physiotherapists (in 4 studies), 19212530 occupational therapists ${ }^{21} 25$ and psychologists $^{21} 22$ (in 2 studies each), and dieticians, ${ }^{27}$ chiropodists, ${ }^{27}$ speech language therapists, ${ }^{21}$ rehabilitation support workers, ${ }^{21}$ optometrists, ${ }^{27}$ and physician assistants $^{20}$ (each in 1 study). The patient groups are shown in table 2. Self-management programmes specifically identified in the studies included Bridges, ${ }^{21}{ }^{25}$ Flinders, ${ }^{22} 29$ Stanford $^{22}$ and a Chronic Obstructive Pulmonary Disease programme. ${ }^{30}$ The remainder of studies referred generally to the adoption or integration of self-management principles or programmes into clinical practice, without naming a specific programme or model.

\section{Data synthesis}

Three main themes about clinician experience and views of being involved in delivery self-management strategies were developed from the data:

- Theme (1) Who is in control? The issue of 'control' arose in all included studies, both implicitly and explicitly, and formed the basis for the first theme. There appeared to be variability in the way that control was discussed, particularly in relation to who has control. Clinicians talked about ways they exercised control over patients as well as the control they expected patients to have over their condition.

- Theme (2) Changing clinician views reflected a necessary transformation of practice experienced by a number of clinicians through working to integrate selfmanagement approaches into their practice.

- Theme (3) Overcoming challenges to change synthesised a range of challenges associated with shifting away from a traditional approach. In particular, a tension appeared to exist around relinquishing control and forming partnerships with patients. However, clinicians reported a range of strategies they found helpful in the process of change.

Each of the themes are presented in detail below with supporting evidence in the form of quotes and extracts taken directly from included papers. Direct quotes from participants of included studies are indicated in italics, followed by the reference number and page number. Interpretation from the authors of included studies is indicated by the extract of text in plain font followed by the reference number and page number.

\section{Theme 1: Who is in control?}

The first theme Who is in control? incorporates the different ways clinicians talked about control, including ways they exercised authority over patients (clinician control) as well as the perceived choices patients make (patient control) in controlling a disease (disease control). Clinicians exercised authority over patients primarily through education and instruction directing the patient to control the disease through changing their behaviour. Data suggest that clinicians believed their role was to provide the necessary information and clear recommendations to patients.

Education is paramount as long as we've imparted... all the knowledge we have... the choice is definitely up to them. (ref. 23, p.195)

Motivation was identified by clinicians to be a critical factor in controlling the disease. In general, clinicians appeared to view motivation as essential for successful self-management, as well as a patient attribute and responsibility.

Motivation is the number one characteristic the patient needs to have for good control, motivated not to eat that second plate of 
Figure 1 Selection of studies.

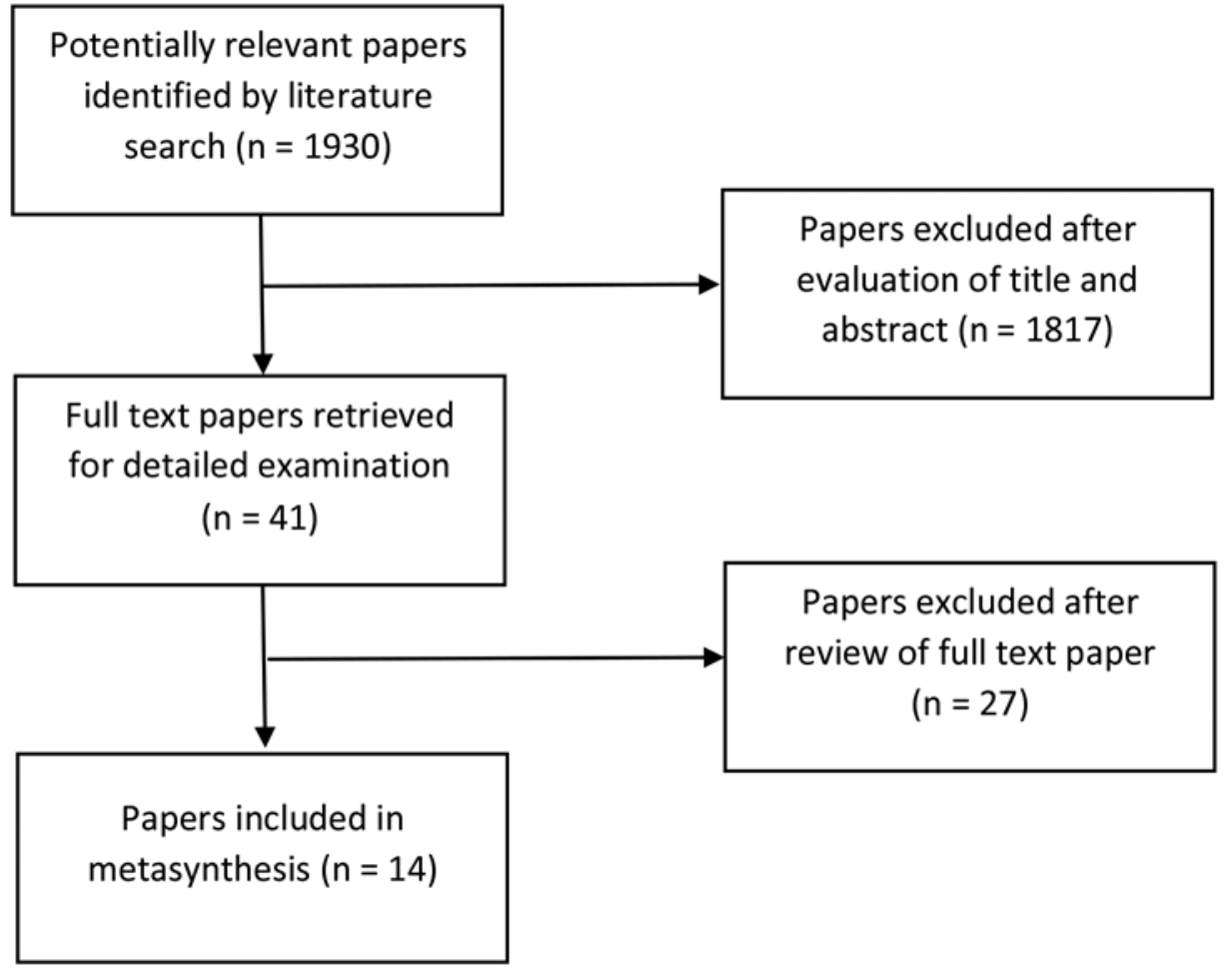

food, not to watch TV but instead go for a walk. (ref. 20, p.664)

Education and instruction appeared to be the key strategies adopted by clinicians to 'motivate' patients. Repetition was adopted as a strategy to "get their point across" (ref. 26, p.1496). There was an assumption that these actions would be sufficient for patients to make recommended changes, which in turn would lead to improved health. For example, clinicians made statements such as, "patients should also be able to adopt healthy behaviours" (ref. 23, p.196), and that "if followed, the recommended treatments would be effective" (ref. 20, p.664). As such, responsibility or blame was often attributed to the patient:

...it's diet they don't keep to or their lifestyle... (ref. 26, p.1496)

[With] some people, you can bang your head against that brick wall until you've knocked yourself out. Some people will come up with excuse after excuse. (ref. 23, p.197)

Clinical markers were used as the primary indicator of successful disease control. The implication was of a linear cause-effect belief where if clinical indicators were poor, it was assumed the patient had not been following recommendations correctly. In such cases, it was not uncommon to label the patient as non-compliant.

A common notation in medical charts when a patient had failed to lower their glucose levels was that the patient had been noncompliant with dietary recommendations. (ref. 20, p.664)
Such labels assumed a simple dichotomy between cooperative versus uncooperative and compliant versus non-compliant; this could not account for nuances or the complexity patients may face living with their condition.

In some cases, when education was perceived to have failed, clinician participants reported resorting to strong persuasion or threats in an attempt to exercise control over patients:

You have to try and barter with them and say, 'Unless you come to me, then we are going to have to refer you on'. (ref. 23, p.196)

Some patients still have to be scared into doing something about their blood sugars. (ref. 26, p.1495)

You will still need to tell some patients that 'unless you stop smoking you're going to die'. (ref. 26, p.1495)

In this theme, there appeared to be an assumption that clinicians own the control. The use of the word 'allowed' in the following quote illustrates this clinician's view that he/she has shifted the control to the patient.

He [patient] was happy to have been allowed to do something and felt in control. (ref. 21, p.95)

In some instances, clinicians interpreted patients' passivity as satisfaction with the clinician directing the clinical encounter.

They're on your patch and they have to play the role, sick role... but they're very vulnerable but also passive. And we quite like 


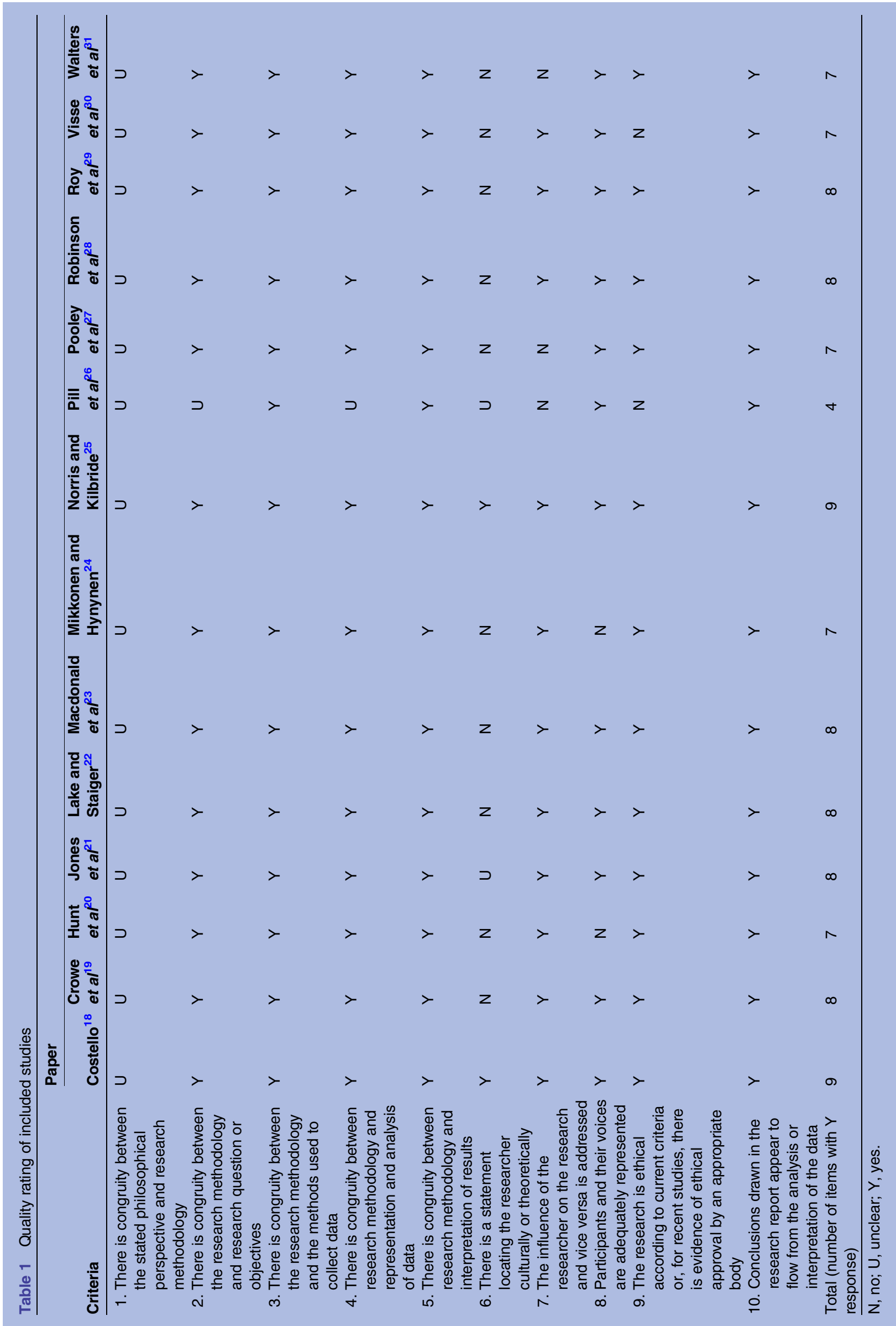




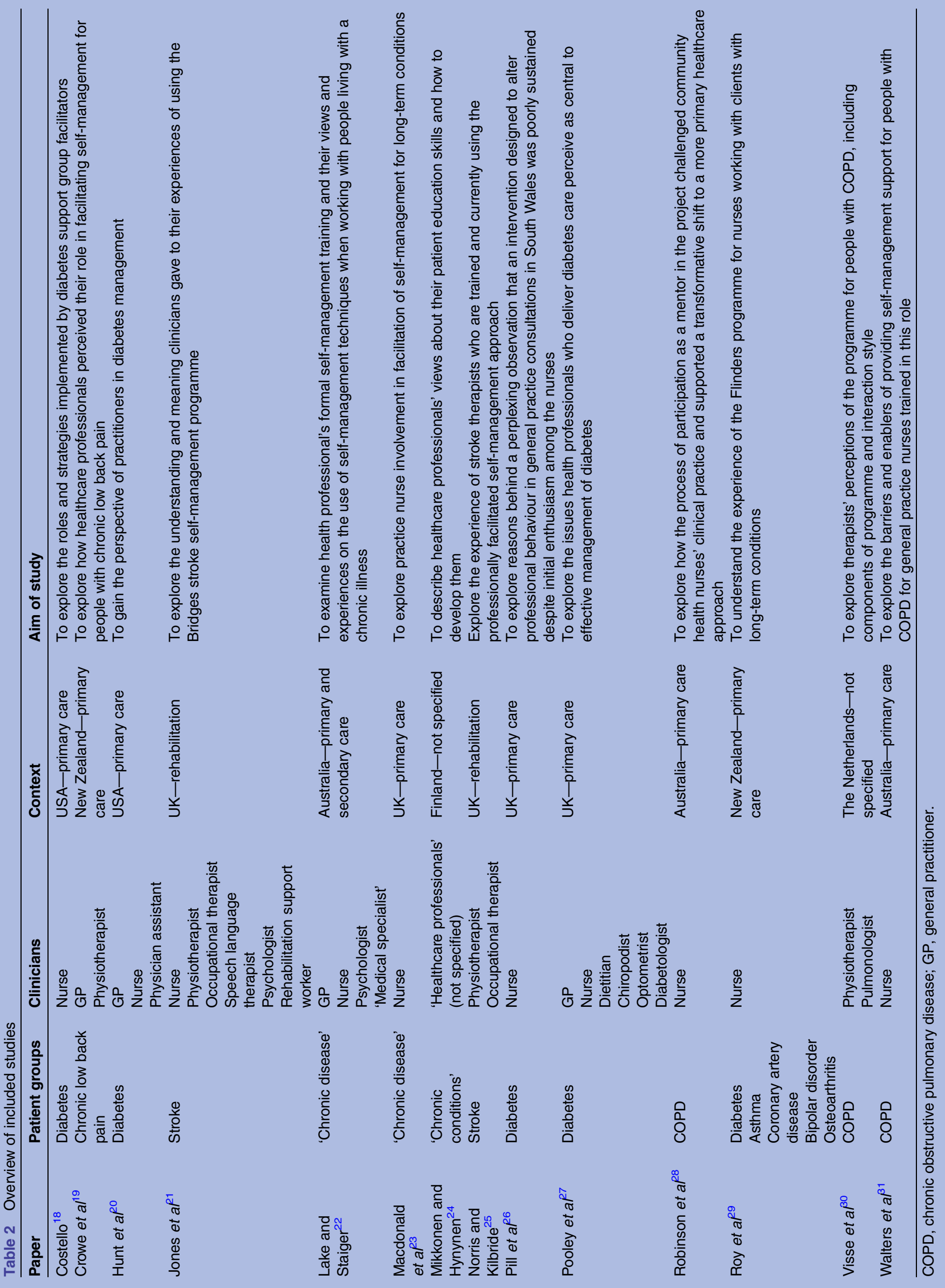


that 'cos then we can get on with our own agenda. (ref. 25, p.34)

\section{Theme 2: Changing clinician views}

Changing clinician views reflects a transformation of practice experienced by some clinicians through integration of self-management approaches into their clinical practice. Data described moving away from an expert and didactic model of interaction to an approach described as a partnership which actively valued patient involvement and expertise.

Their interactions moved from the more traditional 'professionals know best' approach to a partnership where mutual expertise was recognised and valued. (ref. 29, p.147)

It [the intervention method designed to improve patient involvement in their care] has definitely changed my attitude to patient care. I am not so likely to dictate to them now and I think a lot more about involving them and asking how they feel about changing. (ref. 26, p.1495)

Clinicians perceived their previous positioning as an expert with a heavy emphasis on education and a reliance on information provision as the sole ingredient needed to drive a change in behaviour. As a consequence, participants reflected on how they previously did too much talking which limited their ability to listen to patients.

...I talk too much... (ref. 24, p.401)

...shift away from the 'teaching and telling' approach... (ref. 28, p.375)

It made a difference that I listened to [client] and found out what was important for her. Then we worked with that. (ref. 29, p.144)

Key to a changed view was how the clinician perceived the patient. Some clinicians valued the expertise of patients and instead of viewing themselves as the only legitimate source of knowledge now saw that the clinician and the patient each had different kinds of expertise, both of which were important for self-management. Clinicians described a shift in position to where they saw patients as knowing what was important to them; having experienced living with a health condition put patients in a better position than clinicians to determine what would or would not work in the context of their own life.

We must look to ourselves as health professionals, look at how to better help them [patients] meet their requirements, rather than what we think they need... (ref. 28, p.375)

...towards a relationship in which the professional and the patient are equals and represent different kinds of expertise. (ref. 24, p.403)
When therapists described their relationship with clients as a partnership, working together towards a common goal became a priority.

We're in this together, we're going to come to solutions together. (ref. 18, p.182)

GPNs [general practice nurses] saw their role as collaboratively reviewing action plans and supporting patients to achieve their goals. (ref. 31, p.77)

Closely tied up with partnership, was an encouragement or in some cases, more strongly, a facilitation of the active involvement of the patient in the management of their condition.

\section{Now we're encouraging people to become more proactive about their health... (ref. 28, p.376)}

...they endeavoured to alter their therapeutic approach to reflect the need for collaboration and facilitate the leadership of the stroke survivor in their own journey of recovery. (ref. 25, p.35)

Integral to this theme was the acknowledgement of the complexity of patients' lives. The subsequent quote illustrates how clinicians understood the complexity patients grappled with which might lead patients to prioritise other needs above their health needs.

\section{Their problems have nothing to do with diabetes but everything to do with diabetes. (ref. 18, p.181)}

Participants seemed to understand and take into account the disruption, grief and biographical impact that diagnosis of a chronic illness can bring. (ref. 23, p.197)

Some clinicians viewed that optimal medical management of a condition might not be congruent with what was important to a particular patient and so some clinicians recalibrated what might constitute a good outcome for their patients.

Changing clinician views describes a shift towards clinical practice consistent with a model of person-centred practice and away from the more traditional models of practice.

Old values like hierarchy and control are replaced by values as equality and autonomy. (ref. 30, p.370)

The social encounter shifts from one with a focus on admonishment and giving/imposing direction, to collaboration and partnership. It is apparent that the latter are perceived as more caring behaviours, a marked shift from the professional nihilism reported in the literature. (ref. 28, p.376)

Clinicians who perceived the value in listening to patients and understanding patients' perspectives found this led to a shift in professional attitude. Clinicians 
invariably viewed this as a positive change on clinical practice.

\section{Theme 3: Overcoming challenges to change}

The final theme Overcoming challenges to change reflects an articulation of the challenges associated with the paradigm shift that many clinicians experienced when attempting to shift away from a traditional approach. Many of the tensions experienced by clinicians were centred on ideas and/or concepts of sharing or letting go of control.

And for some it's difficult to let go of that sort of 'I'm the physio, I'm the expert. I've got to look at the impairments and make them better, otherwise there are going to be long term implications that this patient doesn't even understand. So it shouldn't be about what they functionally want to do now, it should be me as an expert saying this is what you need to do for the long term.' (ref. 25, p.36)

Reflections on learning centred on the tensions that exist between relinquishing control and encouraging individuals to make choices about goals and influence the direction of therapy. It's hard to get the balance right between encouragement and taking over. (ref. 21, p.96)

One of the challenges that many participants perceived was the need for an observed, conscious shift from talking to listening, which was particularly challenging for many clinicians. They described working hard to change their communication style to one that allowed or encouraged the patient the opportunity to talk and express how they felt, in order to avoid making assumptions about the feelings, needs and preferences of patients.

So you'd almost have to hold yourself back... (ref. 18, p.183)

It makes you realise that (sigh) you've got to give patients a chance to say how I feel today; I think we're not always very good at that, nurses, doctors, carers. (ref. 23, p.196)

Clinicians also specifically talked about needing to avoid the temptation to prevent patients from setting what the clinician perceived as unrealistic goals.

I struggled to resist the urge to gently suggest that their long term goal of mobilising outside was unrealistic. (ref. 21, p.95)

Following the recognition of the challenges associated with a paradigm shift, participants described that the process of shifting from an exclusively or largely biomedically focused paradigm to one that is more personcentred is gradual, in which small changes can be made and built on.

Doctors as well as patients have to grow into these new roles and establish new relationships. Empathy, support, listening to the patient's story and dialogical interaction are as important as giving information and asking for consent. (ref. 30, p.371)
The need for training, which included an introduction to relevant theory and principles of self-management, interactive activities and application to real-world case vignettes, was recognised across a range of studies. Those that did not receive training "expressed concerns that they were working in the dark" (ref. 22, p.65). Those that did receive training perceived that their practice had changed as a result and were able to reflect that prior to the training they, like their current colleagues, did not recognise any need to change their way of practice. Some clinicians, when exposed to a different way of practice, think that it is similar to the way they have been practicing using "common sense knowledge and skills they had built up over time in their day-to-day work with patients" (ref. 31, p.78).

I think that even though we say that we do client centred goal setting, I think that we don't. And I think this is one of the issues with [the approach] is that people say that they do everything that [this approach] does, but it's how you do it. Yeah we'll talk about listening and they'll go 'Yeah yeah yeah yeah, goal setting's collaborative'. Is it? Is it really? Is it really collaborative? Are you really listening to what they're saying? (ref. 25, p.35)

Participants who had received self-management training greatly valued that preparation. In retrospect, the majority did not think that they previously possessed the requisite skills (eg, collaborative communication styles) and attitudes necessary to deliver self-management programmes.

What I have found really useful is that the [self-management] packages that are developed for the client population are probably just as helpful to the professional population because we assume a knowledge base around SM [self-management] that is not there. (ref. 22, p.64)

They equally articulated how the self-management training and use of the resources facilitated a more inclusive and shared approach to rehabilitation and selfmanagement in the longer term. (ref. 25, p.37)

However, participants perceived that training alone was not sufficient to drive a change in the way of practice.

These [group discussions] provided an important venue for the nurses to critically reflect on the issues raised and collaboratively strategise creative responses to seemingly intractable problems to achieve simple yet 'amazing' outcomes. (ref. 28, p.375)

Through reflective practice, core challenges, needs and patient preferences can be better understood. [...] Case reflections offered an opportunity for personal reflection on learning. (ref. 21, p.96)

Appreciating and acknowledging the importance of reflection is one prerequisite for the paradigm shift from the traditional patient education model towards the patient-centred education. (ref. 24, p.403) 
Clinicians noted that dedication of time to practice; a deliberate attempt to focus on skills gained such as collaborative goal setting and setting action plans; and support from colleagues were useful in facilitating a change in the practice over time. Furthermore, the training packages that included a self-reflection component (eg, peer support, case reflections, supervision) appeared to facilitate the transformation of clinical practice, especially if engaged in an ongoing basis.

\section{DISCUSSION}

The key finding of this metasynthesis is the dominant position control had in many clinicians' discussion of selfmanagement approaches, which was used in a variety of contexts. Although the word 'control' is most widely used in recent self-management literature to describe disease control $^{18} 28$ and/or patient autonomy and control, ${ }^{21} 2224$ this study highlighted a tension between these two constructs and indeed with a third-that of clinician control.

Traditional models of practice tend to position the clinician as an expert and as such, puts the clinician in a position of authority over the patient. Data from clinicians with this perspective outlined their attempts to control patient behaviour (aiming to lead to disease control) primarily through education and motivation. Frustration was often expressed by clinicians when this did not lead to the desired or expected outcomes, ${ }^{19} 20232528$ and poor control on the part of the patient was indicated as the central cause of this failure. 18202123252628 These findings provide a critical examination of the role that clinicians play in selfmanagement approaches and may help to propose ways forward in supporting treatment fidelity. Without formal training or regular reflection, self-management approaches may become tools to control (or blame) patients and in doing so may not empower patients to manage their condition. ${ }^{32-34}$ It is possible that such practices with self-management approaches may limit the effectiveness of self-management strategies and contribute to modest improvement in patient outcomes. ${ }^{435}$

This study set out to contribute to how enhancing patient outcomes might be augmented in an area that influences the success of self-management-ourselves and other clinicians. We used robust methodologies to synthesise raw data from multiple studies and incorporate the interpretations of the authors of those studies. The paper is novel in its focus and the findings have potential to influence future self-management approaches in terms of how we can more actively support clinicians to embed self-management principles into practice. Indeed, the findings of this paper offer some insight into the skills that arguably all clinicians require to enact patient self-activation. Our findings are not able to determine the most effective strategies to support clinician skill acquisition, but do highlight strategies that might be tested. We acknowledge the possible nuances that may exist across disciplines and contexts. Our analysis did not indicate that there would be important differences in the clinicians' views in this respect, though this could be explored in more depth in future research. Metasyntheses have been criticised due to the perceived risk of synthesising work that comes from varying philosophical or theoretical positions, which may be deemed incompatible. ${ }^{36}$ In this instance, none of the included papers were transparent about their philosophical positioning making it difficult to address this explicitly and therefore, interpretations should be read with this caution in mind. We did, however, remain cognisant of the individual papers' stated aims and purpose, and papers were read and analysed in that context.

Clinicians who have undergone formal self-management training appeared to wrestle with issues of control. Many clinicians, who recognised their recently changed views and wished to practice in a different way, articulated a tension associated with sharing control with patients. ${ }^{21} 33$ This tension appeared to relate to discarding the dominant hierarchical model of practice and adopting a personcentred approach. Associated with this change is the complexity of balancing protective aspects of care (eg, ensuring patients avoid adverse health consequences), and elements of patient choice and responsibility. Tensions such as this will most likely be encountered repeatedly during the shift in the mode of practice. It could be that the way we think about the relationship of the different aspects of control might help clinicians reconcile the tensions associated with the theme Who is in control? For clinicians, the wrestling for control (related to a dominant medical model) was largely focused on the patient; it was only through the patient that the clinician attempted to exercise control over the disease. However, in other studies, patients reported a different battle: they described wrestling the disease for control over their life. ${ }^{20} 3738$ Disease control could (and arguably should) be thought of as a mutual goal. If it were-it may help clinicians to adjust their position-to 'relinquish control' and emphasise collaboration between clinician and patient. This would reposition ourselves as partners, working with rather than working on patients.

Clinicians described strategies they found helpful in this transition process. In the first instance, it was important to acknowledge the gradual change needed and by implication, acknowledge the time needed to make changes. Making small changes, such as talking less and listening more, were found helpful (albeit difficult) for clinicians. ${ }^{28} 29$ Clinicians valued the self-management training received, particularly in collaborative communication styles and the use of resources (eg, the Bridges workbook). ${ }^{21} 39$ Participants emphasised the need also for dedicated time and deliberate practice of the skills learnt ${ }^{21} 31$ (eg, collaborative goal setting, action planning). Reflection was also reported to be a very useful technique in making further change, both in this study and others. ${ }^{28} 3340$ Clinicians engaged 
in a range of reflective practices, including seeking/providing informal support to peers, ${ }^{31}$ written case reflections ${ }^{21}$ and regular meetings ${ }^{26}$ with peers or supervisor. Motivational interviewing ${ }^{41}$ and the use of theatre ${ }^{42}$ are other strategies proposed to change clinician attitudes and behaviour. These strategies could be investigated further to test whether they can be used more broadly to facilitate a change in the way to practice.

In order to make and sustain changes in practice methods, clinicians required an environment that was conducive or open to change, including the support of colleagues. ${ }^{39}$ In this respect, change is not only necessary at the individual clinician level, but the influence of broader organisational structures ${ }^{43} 44$ also need to be considered. The findings of this study provide tangible opportunities for clinicians to reflect on the way in which we interact with patients. Beyond the suggested strategies, there is also a need to develop an intervention that integrates the recommended strategies with a theoretical model, and also tests the effect on clinician and ultimately patient behaviour.

\section{CONCLUSION}

Self-management approaches are increasingly identified as important for personal health and well-being, and potentially crucial for management of long-term conditions. Our study highlights that strategies may be required to assist clinicians to draw on self-management approaches and use them for 'enabling' new forms of practice methods. Data indicated that clinicians face a number of challenges associated with the paradigm shift that is required for clinicians to share or let go of control. Clinicians found that specific skills and strategies, such as dedicating time to practice reciprocity in communication style, peer support and self-reflection, were helpful to begin a shift in the ways to practice.

Acknowledgements SM was the recipient of a postdoctoral research fellowship from Waitemata during the bulk of this work. The Laura Fergusson Trust (Auckland) part support KM's Chair in Rehabilitation. While all responsibility for the study design and analysis rests with the authors, they are very grateful for the insightful review and challenge from the reviewers who provided most useful feedback and informed the revisions of this work.

Contributors All authors were involved in the concept and design of the work. The literature search was conducted by SM, and inclusion and exclusion decided by SM and NK, with adjudication from KM. All authors were involved in analysis. SM wrote the original draft of the article. All authors participated in redrafting and all have approved the final version of the article. SM is the guarantor of the article.

Funding This research received no specific grant from any funding agency in the public, commercial or not-for-profit sectors.

\section{Competing interests None declared.}

Provenance and peer review Not commissioned; externally peer reviewed.

Data sharing statement No additional data are available.

Open Access This is an Open Access article distributed in accordance with the Creative Commons Attribution Non Commercial (CC BY-NC 4.0) license, which permits others to distribute, remix, adapt, build upon this work noncommercially, and license their derivative works on different terms, provided the original work is properly cited and the use is non-commercial. See: http:// creativecommons.org/licenses/by-nc/4.0/

\section{REFERENCES}

1. Chodosh J, Morton SC, Mojica W, et al. Meta-analysis: chronic disease self-management programs for older adults. Ann Intern Med 2005;143:427-38

2. Kennedy A, Rogers A, Bower P. Support for self care for patients with chronic disease. BMJ 2007;335:968-70.

3. Weingarten SR, Henning JM, Badamgarav E, et al. Interventions used in disease management programmes for patients with chronic illness: which ones work? Meta-analysis of published reports. BMJ 2002;325:925-8.

4. Kennedy A, Bower P, Reeves D, et al. Implementation of self management support for long term conditions in routine primary care settings: cluster randomised controlled trial. BMJ 2013;346:f2882.

5. Lennon S, McKenna S, Jones F. Self-management programmes for people post stroke: a systematic review. Clin Rehabil 2013;27:867-78.

6. de Silva D. Evidence: helping people help themselves. London: Health Foundation, 2011.

7. Kendall E, Ehrlich $\mathrm{C}$, Sunderland N, et al. Self-managing versus self-management: reinvigorating the socio-political dimensions of self-management. Chronic IIIn 2011;7:87-98.

8. Kayes NM, Mudge S, Bright F, et al. Whose behavior matters? Rethinking practitioner behavior and its influence on rehabilitation outcomes. In: McPherson KM, Gibson BE, Leplege A, eds. Rethinking rehabilitation theory and practice. Boca Raton: CRC Press, Taylor \& Francis, 2015:249-71.

9. Lorig KR, Holman HR. Self-management education: history, definition, outcomes, and mechanisms. Ann Behav Med 2003;26:1-7.

10. Jones F, Riazi A. Self-efficacy and self-management after stroke: a systematic review. Disabil Rehabil 2011;33:797-810.

11. Lindsay S, Kingsnorth S, McDougall C, et al. A systematic review of self-management interventions for children and youth with physical disabilities. Disabil Rehabil 2014;36:276-88

12. Buelow JM, Johnson J. Self-management of epilepsy: a review of the concept and its outcomes. Dis Manag Health Outcomes 2000;8:327-36.

13. Thorne S, Jensen L, Kearney $\mathrm{MH}$, et al. Qualitative metasynthesis: reflections on methodological orientation and ideological agenda Qual Health Res 2004;14:1342-65.

14. Tong A, Flemming K, Mclnnes $\mathrm{E}$, et al. Enhancing transparency in reporting the synthesis of qualitative research: ENTREQ. BMC Med Res Methodol 2012;12:181.

15. Thomas J, Harden A. Methods for the thematic synthesis of qualitative research in systematic reviews. BMC Med Res Methodol 2008;8:45.

16. Pearson A. Balancing the evidence: incorporating the synthesis of qualitative data into systematic reviews. Int $\mathrm{J}$ Evid Based Healthc 2004;2:45-64.

17. Irwin S, Winterton M. Qualitative secondary analysis and social explanation. Sociol Res 2012;17:4

18. Costello JF. Roles and strategies of diabetes support group facilitators: an exploratory study. Diabetes Educ 2013;39:178-86.

19. Crowe M, Whitehead L, Jo Gagan M, et al. Self-management and chronic low back pain: a qualitative study. J Adv Nurs 2010;66:1478-86.

20. Hunt LM, Arar NH, Larme AC. Contrasting patient and practitioner perspectives in type 2 diabetes management. West $J$ Nurs Res 1998;20:656-82.

21. Jones F, Livingstone E, Hawkes L. 'Getting the balance between encouragement and taking over'- reflections on using a new stroke self-management programme. Physiother Res Int 2013;18:91-9.

22. Lake AJ, Staiger PK. Seeking the views of health professionals on translating chronic disease self-management models into practice. Patient Educ Couns 2010;79:62-8.

23. Macdonald W, Rogers A, Blakeman T, et al. Practice nurses and the facilitation of self-management in primary care. J Adv Nurs 2008;62:191-9.

24. Mikkonen I, Hynynen M-A. Health care professionals' views about supporting patients' self-management. Health Educ 2012;112:396-405.

25. Norris M, Kilbride C. From dictatorship to a reluctant democracy: stroke therapists talking about self-management. Disabil Rehabil 2014;36:32-8. 
26. Pill R, Rees ME, Stott NC, et al. Can nurses learn to let go? Issues arising from an intervention designed to improve patients involvement in their own care. J Adv Nurs 1999;29:1492-9.

27. Pooley CG, Gerrard C, Hollis S, et al. 'Oh it's a wonderful practice... you can talk to them': a qualitative study of patients' and health professionals' views on the management of type 2 diabetes. Health Soc Care Community 2001;9:318-26.

28. Robinson A, Courtney-Pratt $\mathrm{H}$, Lea $\mathrm{E}$, et al. Transforming clinical practice amongst community nurses: mentoring for COPD patient self-management. J Clin Nurs 2008;17:370-9.

29. Roy DE, Mahony F, Horsburgh M, et al. Partnering in primary care in New Zealand: clients' and nurses' experience of the Flinders Program ${ }^{\mathrm{TM}}$ in the management of long-term conditions. J Nurs Healthc Chronic IIIn 2011;3:140-9.

30. Visse MA, Teunissen T, Peters A, et al. Dialogue for air, air for dialogue: towards shared responsibilities in COPD practice. Health Care Anal 2010;18:358-73.

31. Walters JAE, Courtney-Pratt $\mathrm{H}$, Cameron-Tucker $\mathrm{H}$, et al. Engaging general practice nurses in chronic disease self-management support in Australia: insights from a controlled trial in chronic obstructive pulmonary disease. Aust $J$ Prim Health 2012;18:74-9.

32. Wilson PM, Kendall S, Brooks F. The Expert Patients Programme: a paradox of patient empowerment and medical dominance. Health Soc Care Community 2007;15:426-38.

33. Mudge S, Stretton C, Kayes N. Are physiotherapists comfortable with person-centred practice? An autoethnographic insight. Disabil Rehabil 2014;36:457-63.

34. Rosewilliam S, Roskell C, Pandyan A. A systematic review and synthesis of the quantitative and qualitative evidence behind patient-centred goal setting in stroke rehabilitation. Clin Rehabil 2011;25:501-14
35. Kennedy A, Reeves D, Bower P, et al. The effectiveness and cost effectiveness of a national lay-led self care support programme for patients with long-term conditions: a pragmatic randomised controlled trial. J Epidemiol Community Health 2007;61:254-61.

36. Sandelowski M, Docherty S, Emden C. Focus on qualitative methods. Qualitative metasynthesis: issues and techniques. Res Nurs Health 1997;20:365-71.

37. Robinson L, Newton JL, Jones D, et al. Self-management and adherence with exercise-based falls prevention programmes: a qualitative study to explore the views and experiences of older people and physiotherapists. Disabil Rehabil 2014;36:379-86.

38. Schulman-Green D, Jaser S, Martin F, et al. Processes of self-management in chronic illness. J Nurs Scholarsh 2012;44:136-44.

39. Kennedy A, Rogers A, Bowen R, et al. Implementing, embedding and integrating self-management support tools for people with long-term conditions in primary care nursing: a qualitative study. Int J Nurs Stud 2014;51:1103-13.

40. Schutz S. Reflection and reflective practice. Community Pract 2007;80:26-9.

41. Lal S, Korner-Bitensky N. Motivational interviewing: a nove intervention for translating rehabilitation research into practice. Disabil Rehabil 2012;35:919-23.

42. Kontos PC, Miller K-L, Gilbert JE, et al. Improving client-centered brain injury rehabilitation through research-based theater. Qual Health Res 2012;22:1612-32.

43. Ong BN, Rogers A, Kennedy A, et al. Behaviour change and social blinkers? The role of sociology in trials of self-management behaviour in chronic conditions. Sociol Health IIIn 2014;36:226-38.

44. Rogers A, Kennedy A, Nelson E, et al. Uncovering the limits of patient-centeredness: implementing a self-management trial for chronic illness. Qual Health Res 2005;15:224-39. 